\title{
Assistance of Class Action Research (Car) And Open Journal System (OJS Teachers for Sports and Health Physical Education
}

\author{
Destriana1, Silvi Aryanti², Arizky Ramadhan³ \\ 1, 2, 3 Universitas Sriwijaya \\ Email: 1destriana@fkip.unsri.ac.id, 2silviaryanti@fkip.unsri.aci.id, 3arizkyramadhan@fkip.unsri.ac.id \\ doi https://doi.org/10.36526/gandrung.v2i2.1334

\begin{abstract}
The purpose of this community service is to provide assistance in writing classroom action research (CAR) and the open journal system (OJS) for physical education teachers in Ogan llir District. This community service was carried out online from 20-22 November 2020. The number of participants in this service was 75 physical education teachers consisting of elementary school, junior high school, high school. The methods used in the implementation of the service are lectures, questions and answers, demonstrations, and practice. To see the results of assistance, use a questionnaire to see to what extent this assistance is useful. The results obtained in mentoring the writing of CAR and OJS were that on average $91.8 \%$ of participants could understand the writing of CAR and could use OJS. The results of this service are expected to increase competence as a teacher so that it can improve and improve the quality of physical education learning, especially in Ogan llir Regency
\end{abstract}

Keyword: Assistance, Class Action Research, OJS

Pendahuluan

Penelitian Tindakan Kelas (PTK) merupakan salah satu teknik penelitian yang digunakan agar pembelajaran yang dikelola guru dapat mengalami perbaikan dan peningkatan secara terus menerus, oleh sebab itu melaksanakan PTK erat kaitannya dengan pelaksanaan tugas profesional yang harus guru kuasi. Kualitas pembelajaran dapat dilihat dari perencanaan, proses dan hasil belajar. Proses pembelajaran dapat dianggap suatu sistem sehingga keberhasilan ditentukan oleh banyak komponen, salah satu komponen yang terpenting adalah guru.

Undang-Undang No. 14 Tahun 2005 tentang Guru dan Dosen menyatakan bahwa profesi guru sebagai agen pembelajaran mensyaratkan 4 (empat) kompetensi, yaitu kompetensi pedagogik, kepribadian, sosial, dan profesional. Selain kompetensi ini guru yang profesional akan berusaha meningkatkan kinerjanya. PTK merupakan salah satu upaya yang dapat meningkatkan kualitas peran dan tanggung jawab guru dalam pengelolaan pembelajaran.

Guru harus melakukan PTK dalam pengembangan kurikulum ada empat peran guru yaitu sebagai implementers, adapters, developers, dan researchers. Tugas guru tidak hanya mengimplementasikan berbagai kebijakan, akan tetapi harus dapat menyesuaikan kebijakan tersebut dengan kondisi yang ada kemudian meneliti dan mengembangkannya. Fungsi guru sebagai researchers melalui PTK ialah 
GANDRUNG: Jurnal Pengabdian Kepada Masyarakat ISSN: 2721-6136 (Online)

mengkaji masalah yang dihadapi secara ilmiah yang didasarkan pada bukti nyata di kelas. PTK adalah suatu bentuk penelitian yang bersifat reflektif dengan melakukan tindakan-tindakan tertentu agar dapat memperbaiki dan atau meningkatkan praktek-praktek pembelajaran di kelas secara profesional. Penelitian ini dilakukan ketika proses pembelajaran berlangsung yang bersifat kolaboratif dengan melakukan tindakan-tindakan terhadapt peserta didik (Hanifah, 2014).

PTK merupakan kegiatan penelitian untuk memecahkan permasalahan-permasalahan pembelajaran. Dengan melakukan PTK guru mampu memperbaiki proses pembelajaran melalui kajian terhadap apa yang terjadi di kelasnya. Kegiatan ini memberikan manfaat bagi gutu terutama dalam mendorong guru agar proses pembelajaran yang dihadirkannya dapat berjalan efektif dan efisien (Widayati, 2008).

PTK didefinisikan sebagai suatu bentuk penelitian yang bersifat reflektif dengan melakukan tindakan-tindakan tertentu agar dapat memperbaiki dan meningkatkan praktek-praktek pembelajaran di kelas secara lebih profesional (Sumini, 2017). Khasinah (2013) menambahkan PTK merupakan penelitian yang dilakukan oleh guru (pendidik) di kelas atau tempat guru mengajar yang terfokus pada penyempurnaan proses dan praksis pembelajaran .

Pendampingan penulisan PTK ini sangat penting bagi semua guru, terkhusus guru pendidikan jasmani olahraga dan kesehatan (PJOK) di Kabupaten Ogan llir. Pendampingan penyusunan karya tulis ilmiah PTK perlu dilakukan kepada guru-guru PJOK baik tingkat SD, SMP, SMA di Kabupaten Ogan Ilir karena kenyataan di lapangan banyak guru yang kesulitan dalam menyusun dan menulis karya tulis ilmiah PTK serta kendala teknis bagaimana cara mempublikasi karya tulis ilmiah PTK yang sudah dibuatnya. Hal ini sesuai dengan hasil penelitian Noorjannah (2014) bahwa a) motivasi guru dalam menulis yang rendah; b) tidak memiliki cukup waktu luang; c) kurang pemahaman tentang teknik penulisan; d) kesulitan dalam mencari data; e) gagap teknologi; f) tidak memiliki buku referensi; g) maraknya jasa pembuatan karya tulis; h) kurang berfungsinya kegiatan MGPM dalam sosialisasi penulisan karya tulis.

PTK diharapkan menerbitkan hasil yang bisa digunakan secara global. Hal ini bisa dimungkinkan jika penelitian tersebut dipublikasikan secara online, maka guru-guru PJOK Kabupaten Ogan Ilir masih sangat tidak familiar dengan bagaimana cara mempublikasikan hasil penelitian tersebut pada jurnal bereputasi maka perlu adanya pendampingan dalam penggunaan Open Journal Systems (OJS) sebagai sarana atau media dalam mempublikasikan hasil penelitian tersebut.

OJS adalah sebuah sistem manajeman konten berbasis web yang khusus dibuat untuk menangani keseluruhan proses manajemen publikasi ilmiah dari proses callfor paper, peer review, hingga penerbitan 
GANDRUNG: Jurnal Pengabdian Kepada Masyarakat ISSN: 2721-6136 (Online)

dalam bentuk on-line. OJS is an online journal management and publishing platform that was first launched in 2002 as open source software freely distributed by the Public Knowledge Project (Willinsky, 2005). OJS memudahkan peran pengelola jurnal, editor, reviewer, penulis, dan pembaca, OJS merupakan solusi sumber terbuka untuk mengatur dan menerbitkan jurnal ilmiah secara on-line, This system was developed within a climate of concern among journal editors and staff over the costs and means of moving from print to online editions, as well as over the viability of open access models (by which, for example, authors make articles freely available through online institutional repositories and journals make their content freely accessible to readers). These concerns continue to affect social science and humanities journals published by small societies and groups of scholars (Lorimer, Lynch, \& Provençal, 2006), OJS merupakan sistem pengaturan dan penerbitan jurnal dengan tingkat pengoperasian yang sangat mudah dan dapat didownload secara gratis dan diinstal ke penyedia web lokal.

OJS telah dirancang untuk mengurangi waktu dan tenaga yang disediakan untuk tugas-tugas penulisan dan pengelolaan yang berhubungan dengan mengedit sebuah jurnal sementara meningkatkan record-keeping dan efisiensi proses pengeditan OJS dimaksudkan untuk meningkatkan kualitas keilmiahan dan kualitas umum dalam penerbitan jurnal melalui sejumlah inovasi, dimulai dari pembuatan polis jurnal yang lebih transparan untuk meningkatkan indeks.

Berdasarkan uraian di atas, maka pengabdian ini akan melaksanakan pendampingan penulisan PTK dan langkah teknis publikasi melalui OJS bagi guru-guru PJOK di Kabupaten Ogan Ilir, dengan harapan dapat melakukan penelitian tindakan kelas, menghasilkan karya ilmiah yang dapat dipublikasikan dan dimanfaatkan untuk memenuhi persyaratan pengembangan profesionalnya.

\section{Metode}

Kegiatan dilaksanakan pada tanggal 20-22 November 2020 dari pukul 08.00-16.00 WIB Kegiatan dilaksanakan secara daring karena untuk menghindari penularan covid-19. Metode yang digunakan dalam pelaksanaan kegiatan adalah ceramah dan tanya jawab digunakan oleh tim pengabdian untuk menyampaikan prinsip prinsip PTK, prosedur PTK, implementasi PTK, dan prosedur penulisan laporan PTK. Sebagai pengumpul data digunakan angket sebagai instrumen pendampingan.

Ceramah didukung pemanfaatan laptop untuk menayangkan materi pengabdian dalam waktu terbatas.Selain itu demonstrasi juga digunakan oleh tim pengabdi dengan harapan peserta dapat mulai mempraktekkan penyusunan masalah dalam proses pembelajaran yang dapat dipecahkan melalui PTK, rancangan proposal PTK, hingga penulisan laporan PTK. Untuk mengoptimalkan pelaksanaan 
GANDRUNG: Jurnal Pengabdian Kepada Masyarakat ISSN: 2721-6136 (Online)

pengabdian dilakukan pendampingan oleh tim pengabdi, yaitu dalam penyusunan rancangan proposal PTK dan penulisan laporan PTK dan demonstrasi menggunakan OJS, dan menggunakan metode praktek dengan harapan guru dapat secara langsung memraktikkan pengetahuan yang didapatkan sehingga akan terlihat keberhasilan kegiatan pendampingan. Peserta kegiatan pendampingan berjumlah 75 guru SD, SMP, dan SMA PJOK di Kabupaten Ogan Ilir.

\section{Hasil dan Diskusi}

Hasil yang terlihat dari kegiatan pengabdian kepada masyarakat ini berupa peningkatan pengetahuan guru tentang konsep penulisan penelitian tindakan kelas, tujuan penulisan penelitian tindakan kelas, prinsip penulisan penelitian tindakan kelas, karakteristik penulisan penelitian tindakan kelas dan langkah-langkah dalam membuat penelitian tindakan kelas serta pemahaman tentang OJS. Hasil kegiatan pengabdian ini didapatkan dari angket yang disebarkan dan diisi oleh peserta kegiatan pengabidan. Dalam pelaksanaannya pendampingan tersebut menggunakan metode ceramah, diskusi, tanya jawab, serta praktek. (Ulia et al., 2019) juga menggunakan metode yang sama dalam melakukan pendampingan PTK. Berdasarkan hasil evaluasi umumnya guru-guru PJOK sebagian besar memahami secara teoritis tentang penulisan Penelitian Tindakan Kelas (PTK) dan Penggunaan OJS. Kegiatan pelatihan terlihat pada gambar berikut ini:

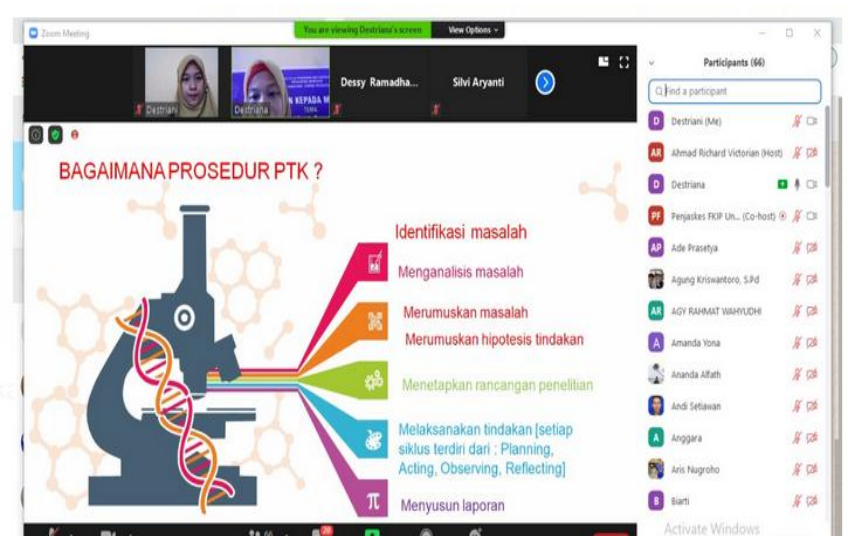

Gambar 1. Pemberian Materi PTK dan OJS 
GANDRUNG: Jurnal Pengabdian Kepada Masyarakat ISSN: 2721-6136 (Online)

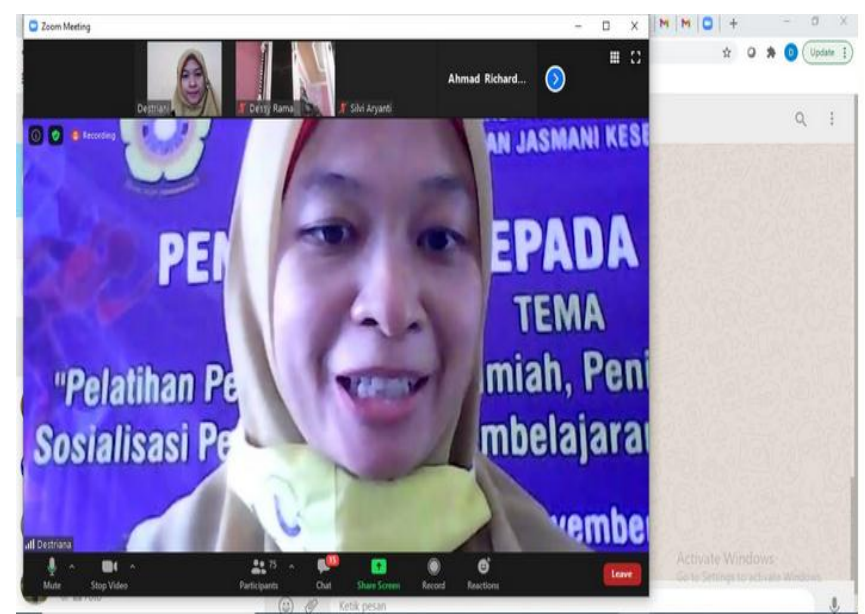

Gambar 2. Pemberian Materi PTK dan OJS

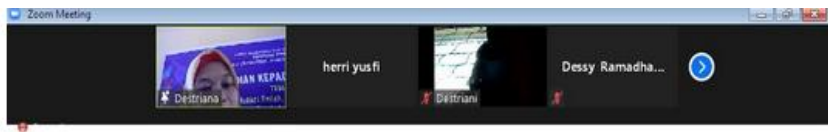

\section{HIPOTESIS TINDAKAN}

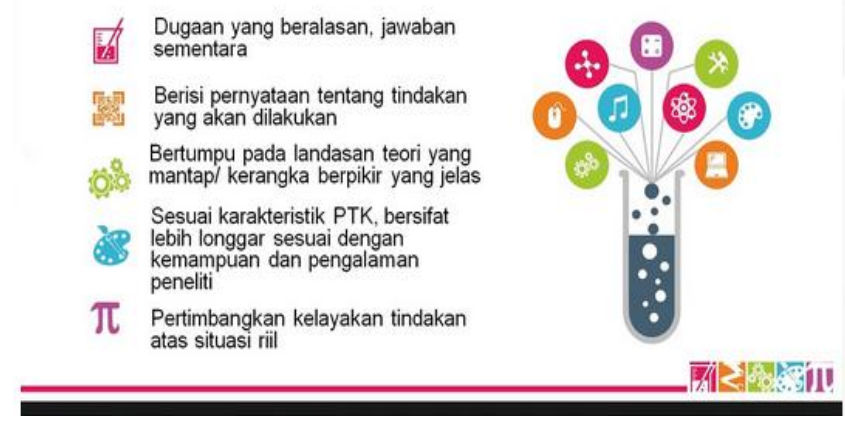

Gambar 3. Pemberian Materi PTK dan OJS

Gambar di atas adalah pelaksaan kegiatan pendampingan yang dilakukan secara daring menggunakan aplikasi Zoom Meeting. Hasil pendampingan dapat diketahui dari hasil evaluasi dengan menggunakan angket. Untuk lebih jelasnya dapat dilihat pada Table berikut ini: berikut ini:

Tabel 1. Data Guru PJOK tentang Hasil Pendampingan Penulisan PTK dan OJS

\begin{tabular}{cccc}
\hline No & Aspek Capaian & $\begin{array}{c}\text { Jumla } \\
\text { h }\end{array}$ & $\begin{array}{c}\text { Persenta } \\
\text { se(\%) }\end{array}$ \\
\hline 1. & Konsep penulisan Penelitian Tindakan Kelas (PTK) & 66 & 88 \\
\hline 2. & Tujuan penulisan Penelitian Tindakan Kelas (PTK) & 68 & 91 \\
\hline 3. & Prinsip penulisan Penelitian Tindakan Kelas (PTK) & 68 & 91
\end{tabular}


GANDRUNG: Jurnal Pengabdian Kepada Masyarakat ISSN: 2721-6136 (Online)

\begin{tabular}{clcc}
\hline 4. & Karakteristik penulisan Penelitian Tindakan Kelas & 68 & 91 \\
& (PTK) & & \\
\hline 5. & Langkah-langkah dalam penulisan Penelitian & 70 & 93,3 \\
& Tindakan Kelas (PTK) & & \\
\hline 6 & Membuat Akun Jurnal Pada OJS & 70 & 93,3 \\
\hline 7 & Cara mensubmit jurnal Pada OJS & 70 & 93,3 \\
\hline 8 & Cara memsubmit/ upload hasil revisi jurnal Pada OJS & 70 & 93,3 \\
\hline & Rata-Rata & & 91,8
\end{tabular}

Berdasarkan hasil evaluasi didapatkan bahwa rata-rata sebesar $91,8 \%$ guru tentang dapat menyusun PTK dan menggunakan OJS yang meliputi pengertian, tujuan, prinsip, karakteristik, tahapan, dan cara menulis PTK serta membuat akun untuk jurnal, submit jurnal dan bagaimana cara mengupload jurnal pada OJS. Hal ini menunjukkan kompetensi tersebut telah dimiliki oleh guru PJOK di Kabupaten Ogan Ilir, Dewi, Rizal, Ardhian, \& Hardinata (2017) juga melakukan pendampingan artikel ilmiah khusus PTK yang bertujuan meningkatkan kompetensi guru.Selain itu Rahmatullah \& Inanna (2019) mendapatkan hasil bahwa terjadi peningkatan pemahaman tentang penulisan PTK setelah diadakan pelatihan. Selain itu Wiganda (2014) dengan tujuan meningkatkan kompetensi dan kemampuan guru tentang PTK.

Hasil pendampingan penulisan PTK dan OJ menunjukkan bahwa semua guru PJOK dapat menyusun PTK dan memiliki akun untuk submit pada jurnal. Seluruh peserta pelatihan dengan jumlah 75 orang yang terdiri dari bermacam-macam asal sekolah dan dari bermacam-macam usia dapat menyusun penulisan PTK dengan baik, bisa dikategorikan guru-guru PJOK yang masih muda yang lebih baik dalam menyelesaikan penulisan tindakan kelas dan menggunakan OJS hal ini dikarenakan faktor dari belum lama guru-guru PJOK menyelesaikan studi di S1 atau S2.

Setelah mengikuti pendampingan PTK guru PJOK di Kabupaten Ogan llir merasa mendapat tambahan pengetahuan dan keterampilan tentang cara menyusun proposal PTK yang nantinya dapat digunakan untuk perbaikan kegiatan pembelajaran di kelas serta menjadi bahan inovasi sebagai seorang guru PJOK. Selain itu hasil PTK dapat dijadikan artikel ilmiah yang dapat dipublikasikan melalui publikasi secara online dengan cara submit melalui OJS. Kegiatan ini sangat bermanfaat bagi guru PJOK mengingat manfaatnya begitu banyak untuk meningkatkan kompetensi sebagai seorang guru PJOK meskipun dalam mempraktekkan penyusunan proposal PTK dan OJS belum semua guru terampil dalam penyusunannya amun setidaknya guru-guru PJOK di Kabupaten Ogan llir telah memahami tentang 
GANDRUNG: Jurnal Pengabdian Kepada Masyarakat ISSN: 2721-6136 (Online)

konsep, cara melaksanakan tindakan dan cara menyusun PTK serta mengetahui bagaimana cara membuat akun, membuat new submission serta mengetahui bagaimana cara mengupload hasil revisi pada OJS.

\section{Kesimpulan}

Setelah pelaksanaan kegiatan penulisan PTK dan sosialisasi OJS umumnya guru-guru PJOK di Kabupaten Ogan llir telah memahami konsep dan tahapan dalam melaksanakannya. Hal ini ditunjukkan dari hasil evaluasi didapatkan rata-rata sebesar $91,8 \%$ peserta dapat menyusun PTK dan menggunakan OJS. Hasil kegiatan tersebut maka beberapa saran yang dapat dijadikan pertimbangan adalah sebagai berikut: Guru PJOK hendaknya mengaktifkan kegiatan musyawarah guru secara rutin dengan kegiatankegiatan yang dapat menambah wawasan pengetahuan dan keterampilan berkaitan dengan kompetensi seorang guru PKOK di Kabupaten ogan llir. Jika memungkinkan mendatangkan narasumber yang professional. Perlu adanya kerjasama dengan lembaga perguruan tinggi untuk melaksanakan pelatihanpelatihan yang kebermanfaatannya untukmeningkatkan profesionalitas guru PJOK, dan Guru PJOK hendaknya selalu belajar untuk meningkatkan bapengetahuan tentang ilmu pengetahuan dan teknologi, baik melalui forum ilmiah maupun belajar secara mandiri.

\section{Daftar Referensi}

Dewi, P. K., Rizal, M. S., Ardhian, D., \&Hardinata, V. (2017).Pelatihan Penulisan Artikel IImiah Berbasis Penelitian Tindakan Kelas Pada Guru SMP. Jurnal Abdi. https://doi.org/10.26740/ja.v2n2.p7-17 Hanifah, N. (2014). Memahami penelitian tindakan kelas: teori dan aplikasinya. UPI Press.

Khasinah, S. (2013).Classroom action research.PIONIR: Jurnal Pendidikan,4(1).

Lorimer, R., Lynch, L., \& Provençal, J. (2006). Augmenting print: Planning for online journal publish-ing by social sciences and humanities journals in Canada. Burnaby, BC: Canadian Association of Learned Journals \& Simon Fraser University. URL: http://www.sshrc.ca/site/about-crsh/publications/caj]_report_e.pdf [March 29, 2010]

Undang-Undang Republik Indonesia No. 14 Tahun 2005 tentang Guru danDosen.

Rahmatullah,\&Inanna. (2019). Pelatihan Penulisan Penelitian Tindakan Kelas Bagi Guru.Jurnal Dedikasi Masyarakat.

Sumini, T. (2017).Penelitian Tindakan Kelas dan Pengembangan Profesi Guru.Tersedia secara online di:https://www.usd.ac.id/lembaga//ppm/f1/3/Jurnal\%20Historia\%20Vitae/vo/24no1april2010/PEN ELITIAN\% 20TINDAKAN\% 20KELAS\% 20Th\% 20sumini. pdf [diakses di Manado, 
GANDRUNG: Jurnal Pengabdian Kepada Masyarakat ISSN: 2721-6136 (Online)

Sulawesi Utara, Indonesia: 24 Agustus 2018].

Susilowati, D. (2018). Penelitian Tindakan Kelas (PTK) Solusi Alternatif Problematika Pembelajaran. Jurnal IImiah Edunomika, 2(01).

Ulia, N., Fironika KD, R., Ismiyanti, Y., Yustiana, S., Jupriyanto, J., \&Cahyaningtyas, A. P. (2019). Pendampingan kelompok guru SD di kecamatan Genuk tentang pemahaman metodologi penelitian pendidikan (action research \& experiment) dan penyusunan artikel jurnal. Indonesian Journal of Community Services.https://doi.org/10.30659/ijocs.1.1.32-47

Widayati, A. (2008). Penelitian tindakan kelas. Jurnal Pendidikan Akuntansi Indonesia, 6(1).

Wiganda, S. (2014). Pelatihan Penelitian Tindakan Kelas Bagi Guru-Guru Se-Jakarta Timur. Sarwahita. https://doi.org/10.21009/sarwahita.111.01

Willinsky, J. (2005). Open Journal Systems: An example of open source software for journal management and publishing. Library Hi Tech, 23 (4), 504-516 